\title{
Health Profiles and Functional Independence in Former Cane Cutters from a Biofuel Plant in Bahia
}

\author{
Jaqueline Silva Veloso, Kaliane Pamponet Prazeres Bomfim, Mabel Barbosa Esteves
}

Bioenergy, College of Technology and Science-FTC, Salvador, Brazil

Email: velosojaqueline@yahoo.com.br

How to cite this paper: Veloso, J.S., Bomfim, K.P.P. and Esteves, M.B. (2019) Health Profiles and Functional Independence in Former Cane Cutters from a Biofuel Plant in Bahia. Occupational Diseases and Environmental Medicine, 7, 124-134. https://doi.org/10.4236/odem.2019.74010

Received: July 29, 2019

Accepted: August 31, 2019

Published: September 3, 2019

Copyright $\odot 2019$ by author(s) and Scientific Research Publishing Inc. This work is licensed under the Creative Commons Attribution International License (CC BY 4.0).

http://creativecommons.org/licenses/by/4.0/

\begin{abstract}
Introduction: Brazil leads the production of sugarcane and its derived commodities, sugar and ethanol. The fact that it is predominantly manually harvested exposes the workers to a variety of health hazards. Since the harvest is a labor activity that exacts from the worker a heavy physical toll, involving the exertion of quick, repetitive movements that intensely overburden both one's muscles and skeletal frame. Objective: To assess the health profile and functional independence in former workers who operated in a biofuel plant in Bahia. Methods: This is a descriptive, exploration-oriented study conducted with 42 workers formerly employed as cane cutters, both male and female and over 18 years old, all of them living in the town of Amélia Rodrigues (BA). The self-administered Nottingham Health Profile (NHP) was used to measure their quality of life, based on the World Health Organization's classification of disabilities; the Functional Independence Measure (FIM) metrics was employed to keep track of functional independence. The FIM focuses on two aspects, motile and cognitive, subdivided further into categories designed to assess individual independence in tackling basic activities effectively and satisfactorily. Results: 42 individuals were assessed, most of them men (54.8\%), predominantly adults (73.8\%) of African descent (61.9\%). Evidence, along with the correlation coefficient to analyze the FIM and the NHP, presents a significance level of 0.05 in the categories: Total NHP, Energy Level, Pain and Physical Abilities. Conclusion: This study found that there is harm to the health of former cane cutters as far as their sleep, energy levels and physical abilities are concerned. With these remarks, the authors expect to motivate health surveillance efforts regarding the risks in those work environments and the associated health issues, so that preventive and interventive public health measures can be implemented.
\end{abstract}




\section{Keywords}

Rural Worker, Health Profile, Functionality

\section{Introduction}

The cultivation of sugarcane in Brazil goes as far back as the colonial period and contributes significantly to the country's economic growth. In the 1970s, with the crisis in economy and the possibility of depletion in oil supplying, countries worldwide looked for new alternative energy sources. In Brazil, the Alcohol National Program (PROÁLCOOL) promoted sugarcane production [1].

Both for being endowed with great energetic potential and for being a renewable energy source, the cultivation of this biomass is still expanding due to its use in the fabrication of ethanol fuel, of which the country is the world's top producer [2].

In the last few years, there has been a considerable growth in the cultivation of sugarcane biomass - a fact that has proved beneficial to climate change. However, both its production process and its transformation into biofuel have been damaging the environment and the health of the workers in their socioeconomic context [3].

Such changes are due to the evolution and growth of the sugarcane sector in Brazil. This large-scale, systemic process of biofuel production (in itself a reflex of the increasing consumption demand) affected the workers' health as well as the biomes' balance [4].

It must be noted that, according to the World Health Organization (WHO), "health is a state of complete physical, mental and social well-being and not merely the absence of disease or infirmity". The concept of quality of life and its relation to health, on the other hand, is vast and lacking in definition. It is, in any case, agreed upon that it must be evaluated subjectively and multidimensionally, so as to include in its scope a concern with both physical and mental health, as well as social relations [5].

Functionality and incapacity are linked to health conditions and as such indicate what a person "can or cannot do in their everyday life", considering the functions of the organs or of the systems and structures in the body, as well as the limitations on the activities and social participation in a person's environment. In this manner, functionally is used in a positive sense, with the dysfunction that the individual manifests [6].

It is necessary to assess quality of life since it is a relevant standard in health, now acknowledged as an important health profile indicator, not less so regarding workers and preventive medicine policies insofar as they help identify what crucially requires immediate solutions. This gathering of data, therefore, is instrumental to further problem-solving efforts, making the work of professionals in the area easier and contributing to the improvement of health as a field [7] 
[8].

In cane cutting, the intense physical demand put upon rural workers creates a series of ostheomyoarticular limitations and impairments in their health that are a consequence of exhausting, repetitive activities; those, in turn, facilitate the development of diseases and somatic manifestations which will alter the cane cutters' health and quality of life [9] [10].

Manually harvesting sugarcane is hard rural labor [11]. In order to execute it the worker must stoop, thus describing an angle narrower than $90^{\circ}$ from their spine relatively to their lower limbs; with one hand they hold a bundle of cane stems while striking the plantation with a machete with the other, close to the ground. It takes between two and three strikes to pull a cane paring out of the soil [12].

Thereby a worker that manages to harvest 12 tons in a day will have walked, in a single day's work, $8.800 \mathrm{~m}$, given 133.332 podão (machete) strikes, and transported all 12 tons worth of cane in $15 \mathrm{~kg}$ bundles at a time. To that effect, this worker will have to bend down and twist their torso about 36.630 times so as to find the proper angle for cutting the cane [13].

Since the individual worker thus bears a heavy workload, exhibits alterations in body posture and exerts repetitive physical tasks, they will eventually suffer several metabolic, endocrine, biomechanical, muscle-related, articular, psychological and cognitive alterations that entail either adaptation or infirmity - the latter occurring whenever the appropriate functional limitations are extrapolated. Such complaints can translate into ostheomyoarticular disfunctions, which result in the cane cutter's mandatory leave from work [14].

The goal of this paper is to examine the health profile and functional independence in former cane cutters who were allotted in a biofuel plant in Bahia.

\section{Methodology}

This is a descriptive study, exploratory in character, on a group of former cane cutters who were employed at the biofuel plant situated in Amélia Rodrigues, a town in the Brazilian state of Bahia. The study was conducted during the year 2016. Amélia Rodrigues is located in the outskirts of Feira de Santana; it has a population of 25.190 and occupies a territory of $173,484 \mathrm{Km}^{2}$, with a population density of 14,520 inhabitants per $\mathrm{km}^{2}$ according to the 2010 Census [15].

The sample consists of 42 individuals. It was so defined for convenience's sake, considering the peculiarities of the case at hand. The cane cutters live in little neighborhoods in the town's rural district, all but cut off from the rest of the municipality; this fact increases the difficulties in controlling and organizing the access to the workers. For that reason, the individuals were approached by the researchers at their homes, which are not far from the crops themselves.

Primarily, a sound truck advertisement was used to recruit interviewees among the workers; on occasion, a participant would inform the researchers of the availability of other subjects nearby that were eligible for the study. 
Former workers who tended the crops as cane cutters up to 2014 were selected. This study is approved by the Research and Ethics Committee at the Science and Technology Faculty (Faculdade de Tecnlogia e Ciências), CAEE: 58832316700005032. All the participants and/or research personnel have signed the Free and Informed Consent Term, as per the Resolution 466/12 issued by the National Committee for Ethics in Research involving human beings.

\subsection{Clinical Aspects and Assessment Instruments}

Data gathering took place between July and September 2016. Sociodemographic data, work and health conditions, and life habits related to potential alterations in respiratory functions were all surveyed, along with the application of the Nottingham Health Profile (NHP) and the Functional Independence Measure (FIM).

The variables taken into consideration in this study are: gender (male or female), age (adult between 25 and 59 years old; and elder over 60 years old), color (black or brown), alcohol-drinking (yes or no), alcohol-drinking frequency (never, socially or daily), period of exposure to cane cutting ( $<10$ years; 10 to 20 years; $>20$ years), period away from cane cutting ( $\leq 2$ years or $>2$ years), reports respiratory disease (yes or no), smoking habits (yes or no), manifests symptoms of respiratory disease (yes or no), and spirometry level (normal, mild or moderate).

\subsubsection{Nottingham Health Profile (NHP)}

With the purpose of assessing quality of life, The Nottingham Health Profile (NHP) is a self-administered questionnaire constituted by 38 items that are based in the classification of disabilities proposed by the World Health Organization; its questions convey a yes/no answer format.

Its items are organized into six categories encompassing energy level (EL), pain (P), emotional reaction (ER), sleep (S), social interaction (SI) and physical abilities (PA). Each positive answer scores [1], while each negative answer amounts to [0], making it up to a maximum score of 38. Employing easily comprehensible language, the NHP provides a simple metrics to the individual's physical, social and emotional health and is considered a clinically valid instrument to discern disfunction levels among different patients, as well as to detect important changes in the patient's health over time [16].

\subsubsection{Functional Independence Measure (FIM)}

The FIM scale is composed of degrees of dependence ranging over 7 levels, being 1 the value that corresponds to complete dependence and 7 the one referring to normal task accomplishment in an independent fashion. According to the scale, the level of functional Independence is classified in the following manner: 1) Complete dependence, 2) Maximal assist, 3) Moderate assist, 4) Minimal assist, 5) Supervision, stimulus or preparation, 6) Modified independence and 7) Complete independence [17]. 
The total FIM can be divided into four sub-scores, varying according to the total obtained score: 1) 18 points: complete dependence (total assist); 2) 19 - 60 points: modified dependence (assist in up to $50 \%$ of the task); 3) $61-103$ points: modified dependence (assist in up to $25 \%$ of the task); 4) $104-126$ points: complete/modified independence [17].

\subsection{Statistical Analysis}

Sociodemographic variables, work and health conditions, and life habits were submitted to a descriptive analysis of the individuals' absolute (n) and relative (\%) frequencies. Average values, standard deviation, minimum and maximum NHP values (along with its categories-energy level, pain, emotional reactions, sleep, social interaction, physical abilities-were all computed.

The Spearman's Correlation Coefficient was used to analyze the correlations between the total FIM and the NHP (along with the latter's categories in which the significance level registers at 0.05). Furthermore, the correlation between FIM and NHP underwent graphic comparison. The study was analyzed with the Stata $12^{\oplus}$ software.

\section{Results}

In Table 1 it was verified that 42 individuals were interviewed. Most of them are male $(54.8 \%)$, predominantly black (61.9\%) adults (73.8\%), 54.8\% of the individuals showed symptoms of respiratory diseases, even though the majority of them identified as non-smokers (78.6\%) In addition to that, the labor exposure period was observed to be of $<$ than 10 years to $57.2 \%$ of the participants, while the period without exposure was $>$ than 2 years $(69.1 \%)$.

However, the study indicates that $80 \%$ of the individuals do not manifest acute disease, confirming a lower rate to respiratory symptoms $(45.2 \%)$ and to moderate obstruction, as seen inspirometry (11.9\%).

Table 2, in turn, shows the NHP categorization with its average, standard deviation, minimum and maximum of its categories (Energy level, Pain, Emotional reactions, Sleep, Social interaction, and Physical abilities).

As for Table 3 and Figure 1, they evidence the Spearman's Correlation Coefficient used to analyze the correlations between the Functional Independence Measure (FIM) and the Nottingham Health Profile and associated categories that happen to register a significance level $<0.05$. They exhibit a high degree of significance for the categories: Total NHP, Energy Level, Pain and Physical Abilities.

In Table 3 we can see the Spearman correlation between Functional Independence Measure and the Nottingham Health Profile. Provided that we have already accounted for the period of exposition to labor, now it must be noted that stratification is established in the "up to 2 years" and the "above 2 years" ranges. The significance value is verified to the category: Pain, p-value (0.05) until the initial two years; and this category presents continuity above two years with p-value (0.00). 
Table 1. Shows the sociodemographic features and life habits of the individuals formerly employed in cane cutting.

\begin{tabular}{|c|c|c|}
\hline Variable & $\mathbf{N}$ & $\%$ \\
\hline \multicolumn{3}{|l|}{ Gender } \\
\hline Male & 23 & 54.8 \\
\hline Female & 19 & 45.2 \\
\hline \multicolumn{3}{|l|}{ Age } \\
\hline Adult & 31 & 73.8 \\
\hline Elder & 11 & 26.2 \\
\hline \multicolumn{3}{|l|}{$\underline{\text { Color }}$} \\
\hline Black & 26 & 61.9 \\
\hline Brown & 16 & 38.1 \\
\hline \multicolumn{3}{|l|}{ Alcohol-drinking } \\
\hline No & 27 & 64.3 \\
\hline Yes & 15 & 35.7 \\
\hline \multicolumn{3}{|c|}{ Alcohol-drinking frequency } \\
\hline Never & 27 & 64.3 \\
\hline Socially & 11 & 26.2 \\
\hline Daily & 4 & 9.5 \\
\hline \multicolumn{3}{|l|}{ Exposure period } \\
\hline$<10$ years & 24 & 57.2 \\
\hline 10 to 20 years & 9 & 21.4 \\
\hline$>20$ years & 9 & 21.4 \\
\hline \multicolumn{3}{|l|}{ Post-exposure period } \\
\hline Up to 2 years & 13 & 30.9 \\
\hline$>2$ years & 29 & 69.1 \\
\hline \multicolumn{3}{|c|}{$\underline{\text { Respiratory disease Respiratória }}$} \\
\hline No & 34 & 80.9 \\
\hline Yes & 8 & 19.1 \\
\hline \multicolumn{3}{|l|}{ Acute respiratory disease } \\
\hline No & 34 & 80.9 \\
\hline Yes & 8 & 19.1 \\
\hline \multicolumn{3}{|l|}{ Smoking habit } \\
\hline No & 33 & 78.6 \\
\hline Yes & 9 & 21.4 \\
\hline \multicolumn{3}{|c|}{$\underline{\text { Resp. disease symptomatic }}$} \\
\hline No & 19 & 45.2 \\
\hline Yes & 23 & 54.8 \\
\hline \multicolumn{3}{|l|}{$\underline{\text { Spirometry }}$} \\
\hline Normal & 24 & 57.1 \\
\hline Mild obstruction & 13 & 31.0 \\
\hline Moderate obstruction & 5 & 11.9 \\
\hline
\end{tabular}




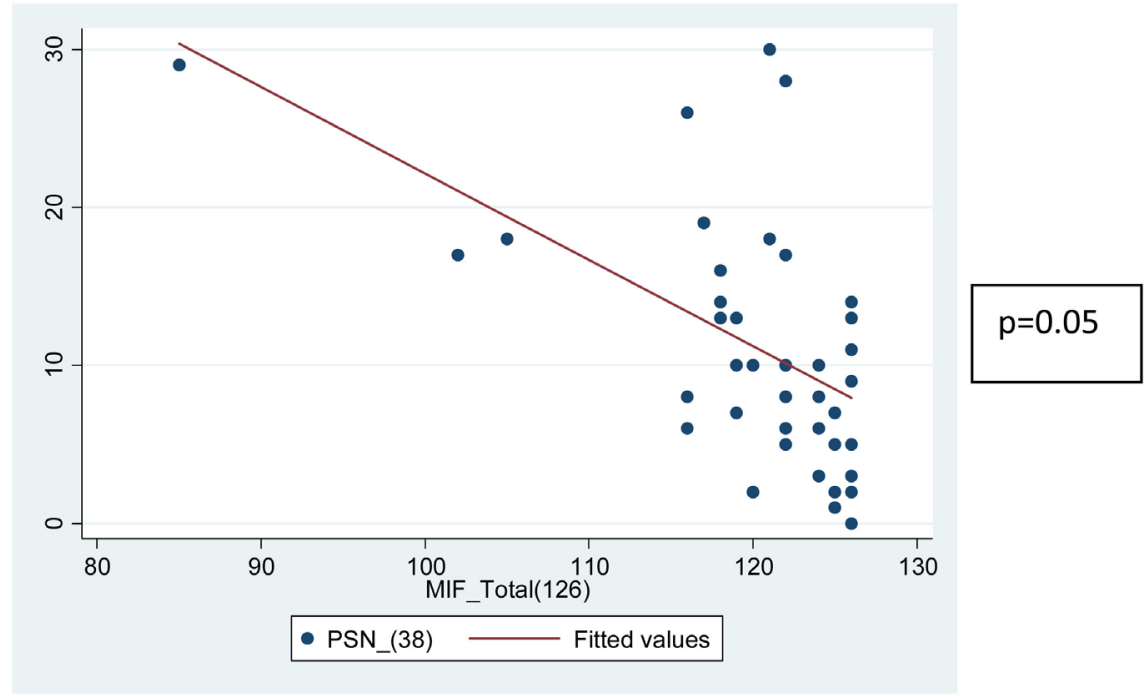

Figure 1. Correlation between Functional Independence Measure (FIM) and Nottingham Health Profile (NHP) in former cane cutters from a biofuel plant. Amélia Rodrigues, Bahia, 2016.

Table 2. Measures average, standard deviation, minimum and maximum Nottingham Health Profile (NHP) categories.

\begin{tabular}{ccccc}
\hline Variables & Average & Standard-dev. & Min. & Max \\
\hline Total NHP & 11.0 & 7.8 & 0 & 30 \\
Energy level & 0.8 & 1.0 & 0 & 3 \\
Pain & 3.3 & 2.5 & 0 & 8 \\
Emotional Reactions & 2.7 & 2.4 & 0 & 8 \\
Sleep & 1.2 & 1.5 & 0 & 5 \\
Social Interaction & 1.1 & 1.2 & 0 & 5 \\
Physical Abilities & 1.8 & 1.7 & 0 & 5 \\
\hline
\end{tabular}

Table 3. Spearman's correlation coefficient (r) between Functional Independence Measure (FIM) and Nottingham Health Profile (NHP) and its categories, stratified time without exposure.

\begin{tabular}{ccccc}
\hline & \multicolumn{2}{c}{ Up to 2 years } & \multicolumn{2}{c}{$>2$ years } \\
\cline { 2 - 5 } & Total FIM & p-value & Total FIM & p-value \\
\hline Total NHP & -0.36 & 0.22 & -0.62 & $0.00^{\star}$ \\
Energy level & -0.23 & 0.44 & -0.4 & $0.03^{\star}$ \\
Pain & -0.55 & $0.05^{\star}$ & -0.65 & $0.00^{\star}$ \\
Emotional reactions & -0.32 & 0.29 & -0.30 & 0.11 \\
Sleep & -0.15 & 0.62 & -0.30 & 0.11 \\
Social interaction & 0.00 & 1.00 & -0.36 & $0.05^{\star}$ \\
Physical Abilities & -0.22 & 0.46 & -0.62 & $0.00^{\star}$ \\
\hline
\end{tabular}

Spearman's Correlation Coefficient $(r) ; p<0.05$. 
According the analysis delivered by means of the Spearman correlation, it follows that energy level p-value (0.03), social interaction p-value (0.05), and physical abilities p-value (0.00) have significance whenever the individuals accumulate more than two years of work activity.

\section{Discussion}

This study examines the health profile and functional independence in former cane cutters who used to work in a biofuel plant in Bahia. Verifying a high prevalence of former workers of this field, the repercussions in their health were analyzed focusing on the population that resides in Amélia Rodrigues.

The aim, therefore, is to profile their health in order to analyze the consequences of the work activity this population was engaged in. It was noticeable from their speech that the cutters' daily routine (during their work hours) was hard and that it started early in the day. From their homes, the workers would walk to the vehicle that was to take them to the crop; they would eventually arrive in the field at approximately $6 \mathrm{AM}$.

Work proper would start by $7 \mathrm{AM}$, when they would then have to face higher temperatures. It was customary to burn the cane before the cutting even started-a practice that contributes to the heating of the soil; at times the work journey would have already started, but the heat would give no sign of receding. On the contrary, the sun would intensify the heat throughout the day. In addition, most of the time, the workers would not wear safety gear-either because they were not able to or because (they would claim) it felt uncomfortable [18].

It is worth noting that the worker in their journey will be exposed to dust and smut derived from the burned cane. Although the burning is a fairly everyday work procedure (one that is performed to facilitate the cutting) it can nevertheless lead to multiple respiratory pathologies in virtue of its elevated concentration of pollutants [19]. Notwithstanding this, it seems that the fact individuals do not presente a history of previous respiratory disease explains the low rates of moderate obstruction found in this case.

The cane cutters are paid for what they deliver. In the 1980s, a cane worker's average revenue was $\mathrm{R} \$ 9.00$ per ton of cane. In 2005 this amount plummeted to $\mathrm{R} \$ 2.50 / t$. This payment system leads to longer, health damaging workdays [18]. It invites occupational hazards, like poor posture, which in turn translate into the workers' symptomatic muscle pains of which they so complain [20].

Stated that a worker not only cuts the cane and its tassel, but also carries it and stows it to be transported by the plant's trucks. A worker who cuts $200 \mathrm{~m}$ worth of cane in a day walks about $5.700 \mathrm{~km}$ and executes about 4 to 14 thousand machete strikes while flexing his legs and back at the same rate. This amounts to repetitive effort and will ultimately impair their physical abilities in the long term [21].

The record of severe pain found in the former cane cutter's NHP took into account the inadequate body posture patterns, sustained for long periods of time 
during work, as well as the repetitive exertions and the excessive work hours. As a whole, they cause the myoarticular disharmonies observed in the workers' performance in and confirmed by the present study [22].

The Nottingham Health Profile is a generic instrument for assessing quality of life and originally developed to that end. This study found that, notwithstanding the fact that the individuals are no longer employed in cane cutting, that activity has impacted their health-pain, emotional reactions, sleep, social interaction and physical abilities being, in this case, the most relevant factors through which said impact is manifested [23]. Such alterations may remain with the individual even after the work activity has ceased, feeding what will, in time, turn into a sequel. This species of disturbance to one's health can, eventually, with repetitive and impairing activity, become irreversible [24].

The Functional Independence Measure presented the lower scores attributed to the items: pain, energy level and physical abilities. The scale demonstrated good estimate of reliability with Spearman's Correlation Coefficient (r); $p<0.05$, tending to the generation of somatic diseases and manifestations which altered the cane cutters' quality of life and health [25].

Assessing quality of life in association with health profile is of great relevance when considering populations of sick individuals; it is nowadays recognized as an important health indicator, no less in the case of workers [7]. It is our understanding that their reality should be assessed multidimensionally to include physical health, psychological health and social relations [5]. Stress, which is an important factor to be observed in cane cutters, arguably points to alterations in emotional reactions and in social interaction [25].

\section{Final Remarks}

More studies have yet to be conducted to guide the reaffirmation, since there remains the need to keep researching in order to confirm the injuries caused by years spent in the cutting of sugarcane. Finally, public policies need to be put in place to prevent the potentially detrimental effects of this work activity. What the present study does achieve is a verification of the short-term damage to the cane cutters' health after their exposure to labor.

\section{Conflicts of Interest}

The authors declare no conflicts of interest regarding the publication of this paper.

\section{References}

[1] Masieiro, G. and Lopes, H.E. (2008) Ethanol and Biodiesel as Alternative Energy Resources: Perspectives from Latin America and Asia. The Revista Brasileira de Política Internacional, 51, 60-79. https://doi.org/10.1590/S0034-73292008000200005

[2] OECD-FAO, Agricultural Outlook 2015-2024. Food and Agriculture Organization of the United Nations. http://www.agri-outlook.org

[3] Turatti, L. (2010) Environmental Citizenship: Political Participation across Borders. 
Human Rights and Political Participation. Free Press, New York, Vol. 1.

[4] Santos, A.P.L. and Lacaz, F.A.C. (2013) Surveillance Actions in Occupational Health and Environment: Analysis of the Performance of the Workers Health Reference Center of Campinas in Gas Stations. Revista Brasileira de Saúde Ocupacional, 38, 230-242. https://doi.org/10.1590/S0303-76572013000200011

[5] Carr, A.J., Gibson, B. and Robinson, P.G. (2001) Measuring Quality of Life Is Quality of Life Determined by Expectations or Experience? BMJ, 322, 1240-1243. https://doi.org/10.1136/bmj.322.7296.1240

[6] OMS (2003) World Health Organization, ICF: International Classification of Functioning, Disability and Health [World Health Organization Collaborating Center for International Classifications, org., Translation Coordination Cassia Maria Buchalla]. Publisher of the University of São Paulo-EDUSP, São Paulo.

[7] Seidl, E.M.F. and Zannon, C.M.L.C. (2004) Quality of Life and Health: Conceptual and Methodological Aspects. Cadernos de Saúde Pública, 20, 580-588. https://doi.org/10.1590/S0102-311X2004000200027

[8] Vasconcellos, L.C.F. and Aguiar, L. (2015) The Management of the Unified Health System and Occupational Health: The Right That One Has and the Right That Is Lost. Health Debate, Rio de Janeiro, 39, 830-840. https://doi.org/10.1590/0103-1104201510600030022

[9] Ficarelli, T.R.A. and Ribeiro, H. (2010) Burning in Sugarcane Fields and Perspectives of Sugarcane Cutters in Macatuba. Health and Society, Sao Paulo, 19, 48-63. https://doi.org/10.1590/S0104-12902010000100005

[10] Alessi, N.P. and Navarro, V.L. (1997) Health and Rural Work: The Case of Sugarcane Workers in Ribeirão Preto Region, São Paulo, Brazil. Cadernos de Saúde Pública, 13, 111-121. https://doi.org/10.1590/S0102-311X1997000600010

[11] Gonçalves, D.B. (2005) Cane Sea, Green Desert? The Dilemmas of Sustainable Development in São Paulo Sugarcane Production. Thesis, Doctorate in Production Engineering, Department of Production Engineering, Federal University of São Carlos, São Carlos, 256f.

[12] Rocha, F.R.L. (2007) Analysis of Risk Factors for Manual and Mechanized Sugarcane Harvesting in Brazil According to the Health Promotion Framework. Thesis Master's Degree, University of São Paulo, Ribeirão Preto College of Nursing, São Paulo.

[13] Wissmann, M.A. (2017) Social Responsibility in Sugarcane Agribusiness in Brazil. 296 f. Thesis Doctorate in Regional Development and Agribusiness, University State of Western Paraná, Toledo.

[14] Júnior, L.C.S.C. (2012) Evaluation of the Health-Related Quality of Life of Sugarcane Cutters in the Off-Season and Harvest. Revista de Saúde Pública, 46, 1058-1065. https://doi.org/10.1590/S0034-89102012000600016

[15] IBGE (Brazilian Institute of Geography and Statistics) (2011). http://saladeimprensa.ibge.gov.br/en/noticias?view=noticia\&id=1\&busca=1\&idnoti $\underline{\mathrm{cia}=2019}$

[16] Salmela, L.F.T., Magalhães, L.C., Souza, A.C., Lima, M.C., Lima, R.C.M. and Goulart, F. (2004) Adapting the Nottingham Health Profile: A Simple Tool for Assessing Quality of Life. Cadernos de Saúde Pública, 20, 905-914. https://doi.org/10.1590/S0102-311X2004000400004

[17] Riberto, M., Miyazaki, M.H., Jorge Filho, D., Sakamoto, H. and Battistella, L.R. (2001) Reproducibility of the Brazilian Version of the Functional Independence 
Measure. Acts of Physiology, 8, 45-52.

http://www.revistas.usp.br/actafisiatrica/article/view/102274/100652

[18] Zanella, J. (2007) The Problems of Sugarcane Advance in São Paulo. Unesp Journal, $21,9$.

[19] Ribeiro, H. (2008) Sugar Cane Burning in Brazil: Respiratory Health Effects. Revista de Saúde Pública, 42, 370-376. https://doi.org/10.1590/S0034-89102008005000009

[20] Coutinho, S.B., Fiorini, N.A. and Ferreira, L.P. (2011) Vocal Symptoms and Laryngeal Sensations in Workers of an Alcohol and Sugar Plant Exposed to Occupational Hazards. Revista da Sociedade Brasileira de Fonoaudiologia, 16, 266-272. https://doi.org/10.1590/S1516-80342011000300006

[21] Alves, J.C.A. (2008) Work and Workers in Sugarcane Cutting: Still the Controversy over Payment for Production and Deaths from Overwork. CCJ-Youth Training Center, São Paulo. https://doi.org/10.11606/s1518-8787.2018052000138

[22] Alves, F. (2006) Why Cane Cutters Die? Health and Society, São Paulo, 15, 90-98. https://doi.org/10.1590/S0104-12902006000300008

[23] Teixeira, S. (2004) Adaptation of the Nottingham Health Profile: A Simple Tool to Assess Quality of Life. Cadernos de Saúde Pública, 20, 905-914. https://doi.org/10.1590/S0102-311X2004000400004

[24] Ferreira, E.S.S., Duran, E.C.M., Daniel, J.G.M., et al. (2014) Capacity for Work among Rural Workers of a Sugar and Alcohol Plant. Revista Enfermagem, 8, 294-302.

http://www.scielo.br/pdf/rsp/v52/pt 0034-8910-rsp-52-87872018052000138.pdf

[25] Lipp, M. (2003) The Four-Phase Stress Model. In: Lipp, M.E.N., Ed., Neuropsychophysiological Mechanisms of Stress. Theory and Clinical Applications, House of the Psychologist, São Paulo, 17-21. 